\title{
Nesidioblastosis-Nonlocalized Hyperinsulinemic Hypoglycemia: A Diagnosis Likely Missed
}

\author{
Parul Gupta ${ }^{1}$, Vivek Agarwal ${ }^{2}$, Deepak Khandelwal ${ }^{3}$, Monika Garg ${ }^{4}$, Deep Dutta ${ }^{5}$, Aakash Garg ${ }^{6}$
}

\begin{abstract}
Endogenous hyperinsulinemic hypoglycemia (EHH) on investigation shows low blood glucose because of excessive endogenous insulin. Adult onset nesidioblastosis is an uncommon cause of EHH in adults and on microscopy shows diffuse proliferation of pancreatic islet cells which bud from ductal epithelium. We herein present a rare case of symptomatic adult onset $\mathrm{EH}$, the cause for which could not be localized on imaging. A 45-year male patient was admitted with recurrent severe hypoglycemia. Biochemical evaluation confirmed EHH (blood glucose $25 \mathrm{mg} / \mathrm{dL}$; simultaneous serum insulin $56.65 \mu \mathrm{lU} / \mathrm{mL}$; C-peptide $10.25 \mathrm{ng} / \mathrm{mL}$ ). Thyroid, cortisol, and other hormone evaluation were normal. All possible preoperative imaging could not localize any abnormal focal lesion in the pancreas. Distal pancreatectomy resulted in complete resolution of hypoglycemia episodes. Histopathology confirmed the diagnosis of nesidioblastosis. Patient was asymptomatic even after 1-year follow-up. In adult patients with EHH with negative imaging studies, nesidioblastosis should be suspected. Symptomatic cases can be successfully treated by distal pancreatectomy with subsequent histopathology giving the final diagnosis.

Keywords: Hypoglycemia, Insulinoma, Islet cell hyperplasia, Nesidioblastosis, Pancreatectomy.

World Journal of Endocrine Surgery (2019): 10.5005/jp-journals-10002-1271
\end{abstract}

\section{INTRODUCTION}

Endogenous hyperinsulinemic hypoglycemia $(\mathrm{EHH})$ on investigation shows low blood glucose and normal to high blood insulin/Cpeptide levels due to excessive endogenous insulin production. The most common cause of EHH is insulinoma, an islet cell tumor, ${ }^{1}$ the incidence of which is approximately 4 per one million patients per year. ${ }^{2}$ The term nesidioblastosis was introduced by Laidlaw in 1938 , for the diffuse proliferation of pancreatic islet cells which were budding from ductal epithelium. ${ }^{3}$ It is usually identified in infants but is uncommon in adults. ${ }^{4}$ Noninsulinoma pancreatogenous hypoglycemic (NIPH) syndrome now incorporates adult onset nesidioblastosis, ${ }^{5}$ which is an uncommon disease, representing about $0.5-5 \%$ cases of $\mathrm{EHH}^{6}{ }^{6}$ In adult nesidioblastosis, there is a functional dysregulation of beta cells, the cause of which is unknown. ${ }^{7}$ It is difficult to distinguish between nesidioblastosis and insulinoma, both clinically and biochemically. Histopathology evaluation clinches the final diagnosis. We herein present a rare case of symptomatic adult onset $\mathrm{EHH}$, the cause for which could not be localized on imaging. Distal pancreatectomy led to clinical improvement with histopathology confirming nesidioblastosis.

\section{Case Description}

A Forty-five-year-old male patient was admitted in emergency department of our hospital with a sudden loss of consciousness along with preceding symptoms of uneasiness and sweating. His blood glucose was $30 \mathrm{mg} / \mathrm{dL}$. The patient regained consciousness after giving intravenous glucose with normalization of blood glucose. As per history given by family members, the patient had been experiencing similar episodes for the past 12 years. The initial episodes used to be mild and were relieved with oral glucose intake. To start, these episodes were primarily in early morning after $6-8$ hours of fasting; however, in past 6 months episodes could occur any time of the day, with progressive increase in severity. Also, the patient had multiple episodes of loss of consciousness in the last few weeks, suggestive of more severe episodes. Patient also
${ }^{1}$ Department of Pathology, Maharaja Agrasen Hospital, New Delhi, India

${ }^{2}$ Department of Endocrine Surgery, Maharaja Agrasen Hospital, New Delhi, India

${ }^{3}$ Department of Endocrinology, Maharaja Agrasen Hospital, New Delhi, India

${ }^{4}$ Department of Radiology, Maharaja Agrasen Hospital, New Delhi, India

${ }^{5}$ Department of Endocrinology, Venkateshwar Hospitals, New Delhi, India

${ }^{6}$ Department of Medicine, Maharaja Agrasen Hospital, New Delhi, India

Corresponding Author: Deepak Khandelwal, Department of Endocrinology, Maharaja Agrasen Hospital, New Delhi, India, Phone: +91 9968878561, e-mail: khandelwalalims@gmail.com

How to cite this article: Gupta P, Agarwal V, Khandelwal D, et al. Nesidioblastosis-Nonlocalized Hyperinsulinemic Hypoglycemia: A Diagnosis Likely Missed. World J Endoc Surg 2019;11(3):91-93.

Source of support: Nil

Conflict of interest: None

complained of significant weight gain of $10 \mathrm{~kg}$ over the last 4 years. There was no history of alcohol intake or intestinal surgery. There was no history of systemic illness or prolonged drug intake. General physical and systemic examination was within normal limits.

Several episodes of severe hypoglycemia (blood glucose $<50 \mathrm{mg} / \mathrm{dL}$ ) were documented in the first few days of hospital admission. During one of the hypoglycemic episodes in hospital (laboratory blood glucose $25 \mathrm{mg} / \mathrm{dL}$ ), investigations revealed elevated serum insulin $(56.65 \mu \mathrm{IU} / \mathrm{mL}$; hyperinsulinemia) and increased C-peptide levels $(10.25 \mathrm{ng} / \mathrm{mL})$. Subsequent thyroid function test and serum cortisol evaluation were within normal limits (Table 1). Multiple imaging studies like contrast-enhanced magnetic resonance imaging (MRI) abdomen, contrast-enhanced 
Table 1: Laboratory investigations in our patient

\begin{tabular}{lll}
\hline Test & Patient value & $\begin{array}{l}\text { Laboratory reference } \\
\text { range }\end{array}$ \\
\hline $\begin{array}{l}\text { Serum cortisol } \\
(7 \mathrm{am}-9 \mathrm{am})\end{array}$ & $8.4 \mu \mathrm{g} / \mathrm{dL}$ & $4.2-38.4 \mu \mathrm{g} / \mathrm{dL}$ \\
Serum TSH* & $2.59 \mu \mathrm{IU} / \mathrm{mL}$ & $0.4-5.5 \mu \mathrm{IU} / \mathrm{mL}$ \\
Serum total T3 & $1.84 \mathrm{nmol} / \mathrm{L}$ & $0.9-2.8 \mathrm{nmol} / \mathrm{L}$ \\
Serum total T4 & $87.53 \mathrm{nmol} / \mathrm{L}$ & $58-161 \mathrm{nmol} / \mathrm{L}$ \\
Serum insulin & $2.3 \mathrm{U} / \mathrm{mL}$ & Negative $\leq 15 \mathrm{U} / \mathrm{mL}$ \\
antibodies & & \\
Serum IGF-1** & $147 \mathrm{ng} / \mathrm{mL}$ & $69-224 \mathrm{ng} / \mathrm{mL}$ \\
\hline
\end{tabular}

*Thyroid stimulating hormone

**Insulin-like growth factor-1

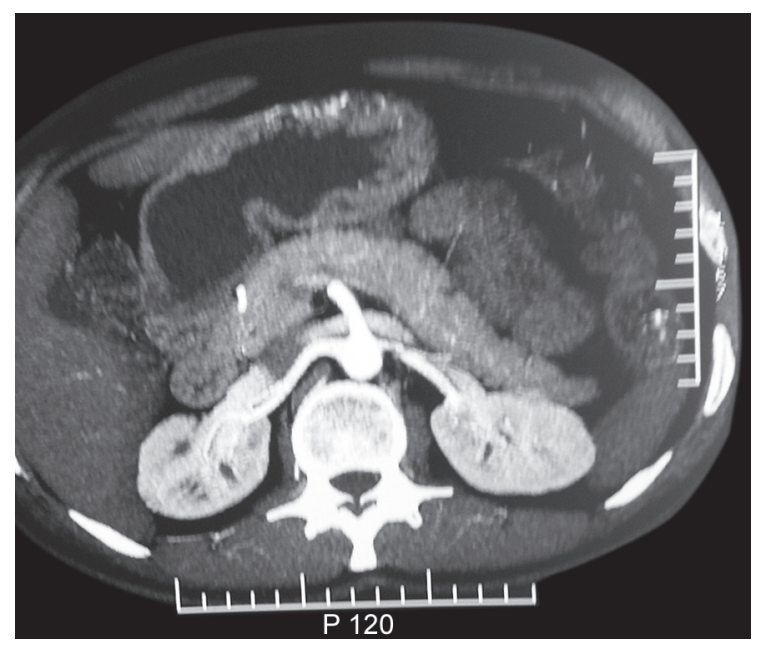

Fig. 1: Contrast computed tomography angiography abdomen showing normal pancreas
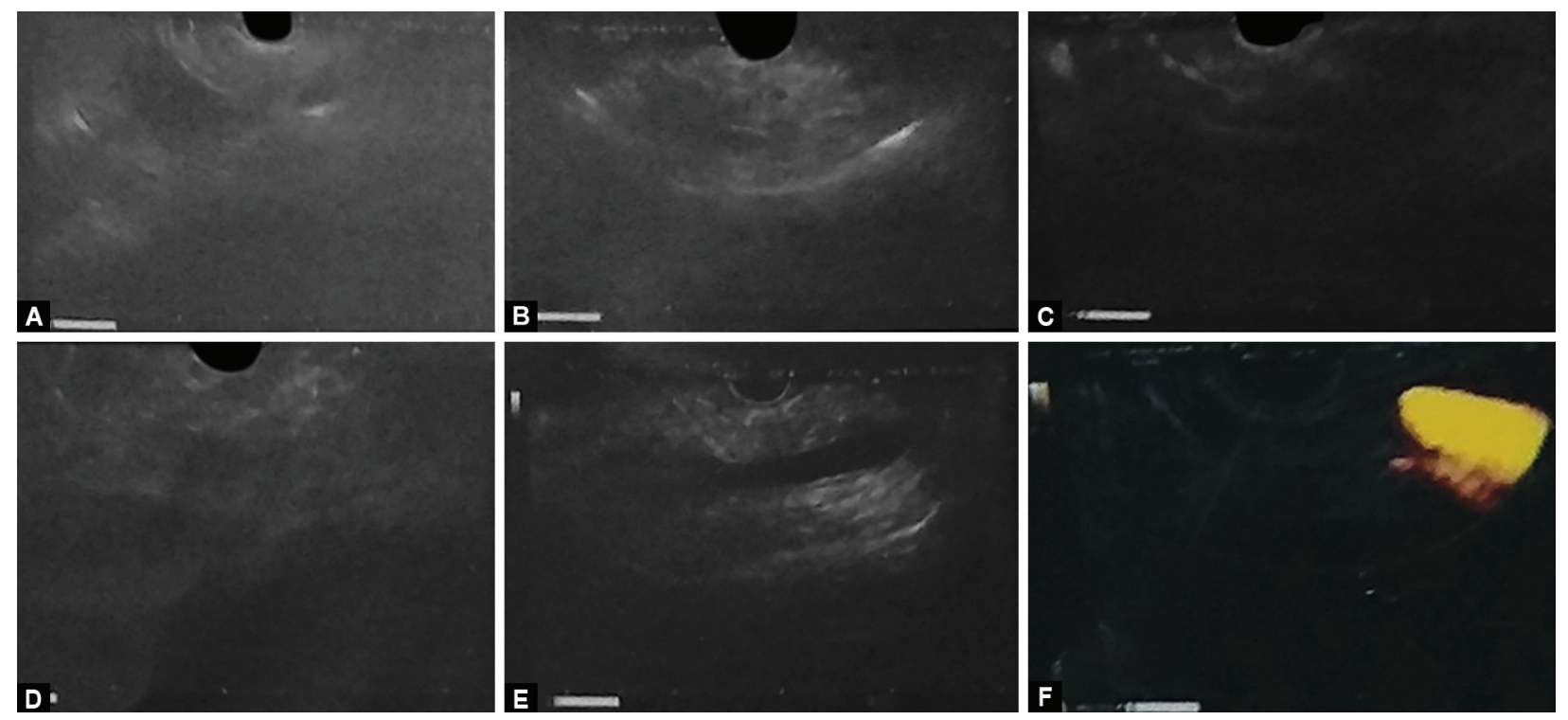

Figs 2A to F: Endoscopic ultrasound showing normal pancreas

computed tomography (CT) angiography abdomen (Fig. 1), and endoscopic ultrasound abdomen (Fig. 2) could not localize any abnormal focal lesion in the pancreas, or anywhere else in the body.

After informed consent, decision was taken for exploratory laparotomy. Intraoperative bidigital palpation and intraoperative ultrasonography (USG) did not reveal any tumor. A left distal pancreatectomy up to mesenteric vein was done. Grossly, the pancreatic tissue measured $6 \mathrm{~cm}$ by $4 \mathrm{~cm}$ by $2 \mathrm{~cm}$. No lesion was detected on thin serial slicing. Multiple sections were taken. Microscopic examination revealed normal exocrine component made up of lobular units of acini and ducts and endocrine component made up of Islets of Langerhans. The islets were increased in number and average diameter (Fig. 3). No cellular or nuclear atypia was seen. A diagnosis of hyperplasia of Langerhans islets or nesidioblastosis was made. Postoperatively, patient did not experience any further hypoglycemic episodes in hospital and blood glucose levels were normal. Last evaluated, 1 year postsurgery, no hypoglycemic symptoms were experienced by the patient.

\section{Discussion}

The patients of EHH clinically present with Whipple's triad, consisting of hypoglycemic symptoms, documented hypoglycemia (blood glucose levels $<50 \mathrm{mg} / \mathrm{dL}$ ), and correction of hypoglycemia leading to immediate relief of symptoms. ${ }^{8}$

Hypoglycemia is responsible for clinical manifestations of $\mathrm{EHH}^{9}$ and hypoglycemic symptoms are grouped in two major categories, adrenergic or neuroglycopenic. Adrenergic symptoms, such as diaphoresis, weakness, nausea, tremor, anxiety, warm sensations, and palpitations, are because of release of catecholamines. ${ }^{2}$ Loss of consciousness, diplopia, blurred vision, confusion, abnormal behavior, and amnesia are the neuroglycopenic symptoms. Endogenous hyperinsulinemia (serum insulin $\geq 3 \mu \mathrm{lU} / \mathrm{mL}$ and serum C-peptide $\geq 0.6 \mathrm{ng} / \mathrm{mL}$ ) in the presence of concomitant hypoglycemia (blood glucose $\leq 50 \mathrm{mg} / \mathrm{dL}$ ) clinches diagnosis of $\mathrm{EHH}$, regardless of whether hypoglycemic symptoms occur in the fasting or postprandial state or after exercise. ${ }^{9}$ 


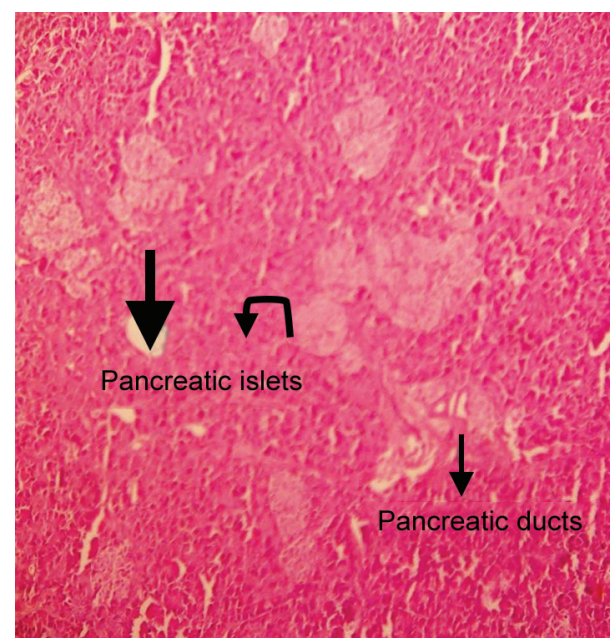

Fig. 3: Hematoxylin and eosin (40x) hyperplasia of pancreatic islets close to pancreatic ducts

Our patient also experienced severe neuroglycopenic symptoms any time of the day with loss of consciousness with documented plasma glucose levels as low as $25 \mathrm{mg} / \mathrm{dL}$ during the episodes. Also, the plasma insulin levels and also C-peptide levels were high during these hypoglycemic episodes. Henceforth, a diagnosis of EHH was made in our patient. Multiple imaging studies including endoscopic ultrasound and contrast CT angiography abdomen as well as intraoperative imaging studies failed to localize any tumor in the pancreas.

Histopathology of thin sections showed normal exocrine component made up of lobular units of acini and ducts and endocrine component made up of islets of Langerhans. The islets were increased in number and average diameter (Fig. 3). There are no universally agreed upon diagnostic criteria of pancreatic islet cell hyperplasia. Rindi and Solcia ${ }^{10}$ defines pancreatic islet cell hyperplasia as an expansion of the endocrine cell mass to more than $2 \%$ (in adults) or $10 \%$ (in infants) of the total pancreatic mass. As the detailed pancreatic morphometry in a clinical specimen is difficult, so there is subjectivity in the diagnosis of pancreatic islet cell hyperplasia. An increase in islet numbers and an islet size large than $250 \mu \mathrm{m}$ in diameter are taken as evidence of pancreatic islet cell hyperplasia in most previous studies. ${ }^{11,12}$ The average diameter of islets in our case was also more than $250 \mu \mathrm{m}$. Therefore, histopathology clinched the final diagnosis of hyperplasia of Langerhans islets or nesidioblastosis.

Another cause of EHH is insulin autoimmune syndrome which shows presence of autoantibodies to native insulin or the insulin receptor. ${ }^{13}$ Insulin autoimmune syndrome is also uncommon, and only scattered cases have been reported worldwide. ${ }^{14}$ In our patient, the insulin antibodies were very low (Table 1).

Noninsulinoma pancreatogenous hypoglycemic syndrome ${ }^{5}$ now includes adult onset nesidioblastosis. The association between bariatric surgery and NIPH is controversial. Hypoglycemia after bariatric surgery occurs commonly and is mostly due to dumping syndrome; ${ }^{15}$ however, in a minority of patients hypoglycemia can only be controlled by partial pancreatectomy. ${ }^{15}$

\section{Conclusion}

In adult patients with $\mathrm{EHH}$ with negative imaging, adult onset islet cell hyperplasia (nesidioblastosis) should always be suspected. Concomitant testing for plasma insulin and C-peptide levels during the hypoglycemic episodes clinches the diagnosis of EHH. Symptomatic cases can be successfully treated by distal pancreatectomy with subsequent histopathology giving the final diagnosis.

\section{References}

1. Service FJ. Diagnostic approach to adults with hypoglycemic disorders. Endocrinol Metab Clin North Am 1999;28(3):519-532. DOI: 10.1016/S0889-8529(05)70086-4.

2. Grant CS. Insulinoma. Best Pract Res Clin Gastroenterol 2005;19:783798. DOI: 10.1016/j.bpg.2005.05.008.

3. Jabri AL, Bayard C. Nesidioblastosis associated with hyperinsulinemic hypoglycemia in adults: review of the literature. Eur J Intern Med 2004 Nov;15(7):407-410. DOI: 10.1016/j.ejim.2004.06.012.

4. Anlauf $M$, Wieben $D$, Perren $A$, et al. Persistent hyperinsulinemic hypoglycemia in 15 adults with diffuse nesidioblastosis: diagnostic criteria, incidence, and characterization of beta-cell changes. Am J Surg Pathol 2005;29(4):524-533. DOI: 10.1097/01.pas.0000151617.14598.ae.

5. ServiceFJ,NattN, Thompson GB, etal.Noninsulinomapancreatogenous hypoglycemia: a novel syndrome of hyperinsulinemic hypoglycemia in adults independent of mutations in Kir6.2 and SUR1 genes. J Clin Endocrinol Metab 1999;84(5):1582-1589. DOI: 10.1210/jc.84.5.1582.

6. Ramírez-González LR, Sotelo-Álvarez JA, Rojas-Rubio P, et al. Nesidioblastosis in the adult: a case report. Cir Cir 2015;83(4):324-328. DOI: 10.1016/j.circen.2015.09.006.

7. Dravecka I, Lazurova I. Nesidioblastosis in adults. Neoplasma 2014;61(3):252-256. DOI: 10.4149/neo_2014_047.

8. Field JB. Insulinoma. In: Mazzaferri EL, Samaan NA. Endocrine tumours. Boston: Blackwell Scientific publications; 1993. pp. 497-530.

9. De Santibañes M, Cristiano A, Mazza O, et al. Endogenous hyperinsulinemic hypoglycemia syndrome: surgical treatment. Cir Esp 2014;92(8):547-552. DOI: 10.1016/j.ciresp.2013.04.025.

10. Rindi G, Solcia E. Endocrine hyperplasia and dysplasia in the pathogenesis of gastrointestinal and pancreatic endocrine tumors. Gastroenterol Clin North Am 2007;36(4):851-865. DOI: 10.1016/ j.gtc.2007.08.006.

11. Weidenheim KM, Hinchey WW, Campbell WGJr. Hyperinsulinemic hypoglycemia in adults with islet-cell hyperplasia and degranulation of exocrine cells of the pancreas. Am J Clin Pathol 1983;79(1):14-24. DOI: 10.1093/ajcp/79.1.14.

12. Starke A, Saddig C, Kirch B, et al. Islet hyperplasia in adults: challenge to preoperatively diagnose non-insulinoma pancreatogenic hypoglycemia syndrome. World J Surg 2006;30(5):670-679. DOI: 10.1007/s00268-005-0543-6.

13. Lupsa BC, Chong AY, Cochran EK, et al. Autoimmune forms of hypoglycemia. Medicine (Baltimore) 2009;88(3):141-153. DOI: 10.1097/ MD.0b013e3181a5b42e.

14. Uchigata $Y$, Hirata $Y$, Iwamoto $Y$. Insulin autoimmune syndrome (hirata disease): epidemiology in Asia, including japan. Diabetol Int 2010;1:21-25. DOI: 10.1007/s13340-010-0001-z.

15. Service GJ, Thompson GB, Service FJ, et al. Hyperinsulinemic hypoglycemia with nesidioblastosis after gastric-bypass surgery. N Engl J Med 2005;353(3):249-254. DOI: 10.1056/NEJMoa043690. 